\title{
The remarkable story of a wonder drug, which now comes to an end in the primary prevention setting: say bye-bye to aspirin!
}

\author{
Marco Valgimigli* \\ Swiss Cardiovascular Center Bern, University of Bern, Switzerland \\ Online publish-ahead-of-print 27 December 2018
}

This editorial refers to 'Efficacy and safety of aspirin for primary prevention of cardiovascular events: a meta-analysis and trial sequential analysis of randomized controlled trials’, by A.N. Mahmoud et al., on page 607.

Aspirin is to date the most used drug worldwide and, in 2018, with some dispute about its real birth date, celebrated its 121st birthday; 2018 will most probably be remembered as the year when aspirin came of age, whereby multiple studies re-examined, and at least partially questioned, its risk/benefit ratio in various clinical settings. ${ }^{1-4}$ While aspirin remains the cornerstone treatment for secondary prevention in patients with established cardiovascular disorders, three large, independent, and high quality randomized controlled trials have shed new light on aspirin in primary prevention. ${ }^{2-4}$ These recent results now have to be incorporated within the context of previously existing evidence, which altogether questions the somewhat liberal use of aspirin that has so far been recommended by some, ${ }^{5}$ but not by other, guidelines committees. ${ }^{6}$

In this issue of the European Heart Journal, Mahmoud and colleagues furnish the findings on a meta-analysis and trial sequential analysis of randomized trials evaluating the efficacy and safety of aspirin among patients without prior known history of atherosclerotic cardiovascular disease. ${ }^{7}$ A total of 11 studies with 157248 participants met the pre-defined inclusion criteria, amongst which were (i) a randomized study design; (ii) comparing aspirin vs. placebo/no aspirin control; (iii) in adult patients without prior history of atherosclerosis; and (iv) including 500 patients or more. It should be emphasized that unlike some previous meta-analyses, ${ }^{8}$ which also were claimed to focus on primary prevention, studies including patients with known atherosclerosis and peripheral vascular disease without having yet experienced an ischaemic event or revascularization (the so-called 1.5 prevention setting) had been excluded for the analysis. Yet, a sensitivity analysis, which also included patients with an established atherosclerotic disorder, mainly in the peripheral system, is provided and yields almost identical implications for practice.

This updated meta-analysis focused on mortality as the principal endpoint. This did not differ between the aspirin and control groups [4.6\% vs. $4.7 \%$; relative risk (risk ratio $(R R))=0.98,95 \%$ confidence interval $(\mathrm{Cl}) 0.93-1.02, P=0.30]$, without heterogeneity across studies and no signal of any treatment effect at interaction testing across pre-defined subgroups including the 10-year risk, diabetes, midenrolment year, aspirin dose, risk of bias, and follow-up duration.

The incidence of major bleeding was higher with aspirin, yielding a $47 \%$ higher $\mathrm{RR}$ and a number needed to harm $(\mathrm{NNH})$ in the range of 250.

Similarly, the risk of intracranial bleeding, which was a pre-defined component of the major bleeding definition in all except one study, ${ }^{9}$ was increased with a $33 \%$ relative and $0.1 \%$ absolute $(\mathrm{NNH}=1000)$ difference.

Cardiovascular mortality or stroke did not differ in patients with or without aspirin, which seriously contributes to the unfavourable risk/benefit profile of aspirin in the primary prevention setting.

However, the incidence of myocardial infarction (MI) was lower with aspirin $[2.0 \%$ vs. $2.3 \%, 95 \% \mathrm{Cl} 1.7-2.8 \%$; $\mathrm{RR}=0.82,95 \% \mathrm{Cl}$ $0.71-0.94, P=0.006$, number needed to treat $(N N T)=333]$. One may wonder whether trading a single $\mathrm{Ml}$ for bleeding would be an acceptable option. The comparative prognostic implications of bleeding vs. a non-fatal Ml for mortality have been investigated at least in the secondary prevention setting and, unsurprisingly, the outcomes depend on the severity of bleeding, with intracranial episodes greatly exceeding the prognostic role of an $\mathrm{Ml}$ in terms of mortality. ${ }^{10}$ Yet, the key upstream question remains of whether the effect of aspirin on $\mathrm{Ml}$ prevention is real and reproducible in contemporary practice. When looking at the current pooled analysis, the effect size of aspirin on $\mathrm{Ml}$ was characterized by a high degree of heterogeneity between the studies included $\left(I^{2}=67 \%\right)$ and a secondary analysis excluding

\footnotetext{
The opinions expressed in this article are not necessarily those of the Editors of the European Heart Journal or of the European Society of Cardiology.

† doi:10.1093/eurheartj/ehy813.

* Corresponding author. Swiss Cardiovascular Center Bern, University of Bern, CH-3010 Bern, Switzerland. Tel: +41 316329653 , Fax: +41 316324771 , Email: marco.valgimigli@insel.ch Twitter handle: @vlgmrc

Published on behalf of the European Society of Cardiology. All rights reserved. @ The Author(s) 2018. For permissions, please email: journals.permissions@oup.com.
} 


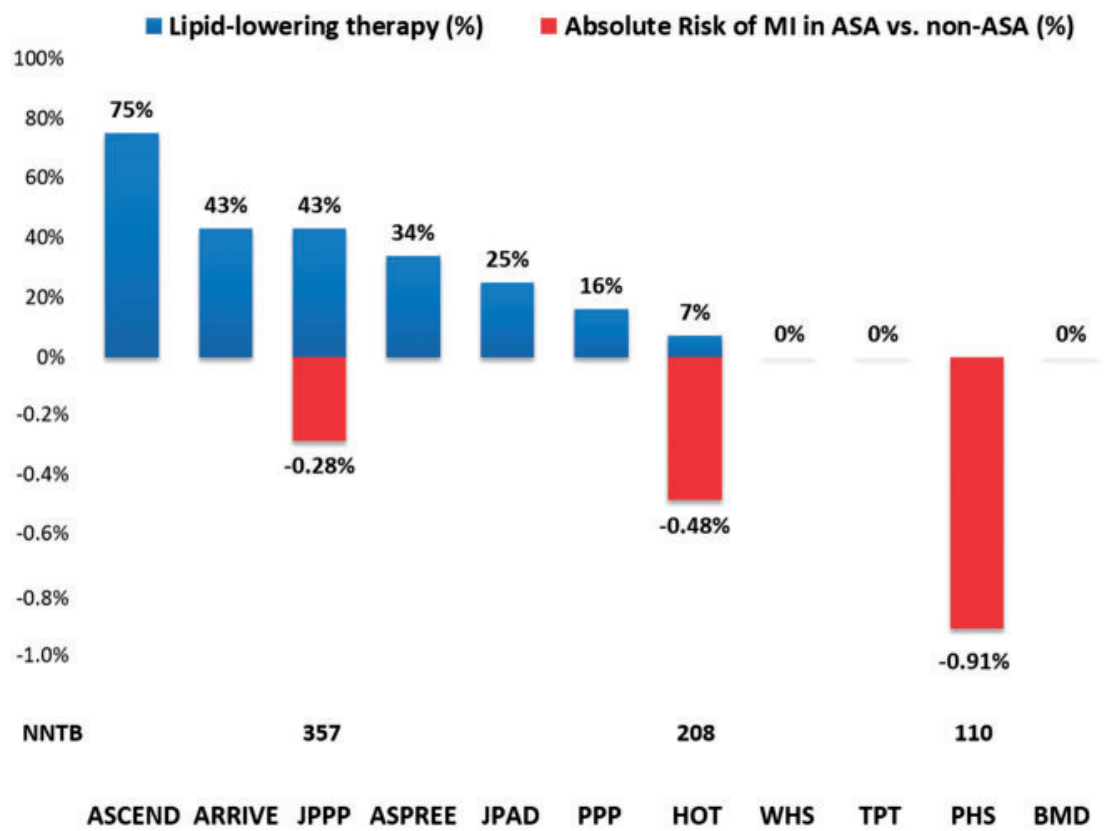

Figure I Lipid-lowering therapy use and absolute risk reduction of myocardial infarction across 11 trials evaluating aspirin in primary prevention. The 11 trials have been sorted based on the proportion of patients treated with lipid-lowering agents; the corresponding absolute risk reduction of myocardial infarction (MI) with aspirin (ASA) as compared with non-aspirin is shown for each included study if found to be significant at each single trial level. ASCEND, A Study of Cardiovascular Events in Diabetes; ARRIVE, Aspirin to Reduce Risk of Initial Vascular Events; ASPREE, Aspirin in Reducing Events in the Elderly; JPAD: Japanese Primary Prevention of Atherosclerosis With Aspirin for Diabetes; JPPP, Japanese Primary Prevention Project; WHS, Women's Health Study; PPP, Primary Prevention Project; TPT, Thrombosis prevention trial; HOT, Hypertension Optimal Treatment; PHS, Physicians' Health Study; BMD, British male doctors.

older trials with mid-enrolment year prior to 2000 showed the lack of aspirin benefit even on Mls in more recent trials ( $R R=0.90,95 \%$ $\mathrm{Cl}$ 0.79-1.02, $P=0.10)$. This observation may have multiple and not necessarily mutually exclusive explanations. Mahmoud and colleagues place emphasis on the fact that old studies pre-dated the universal definitions of $\mathrm{Ml}$ and used relatively insensitive cardiac markers for the diagnosis of an MI.

If one plots the use of statins and the relative risk reductions for $\mathrm{MI}$ across the 11 included studies, an obvious association emerges between no or minimal use of statins and greater absolute effect of aspirin on Ml prevention (Figure 1).

Among the contemporary studies evaluating aspirin in primary prevention, only the Japanese Primary Prevention Project observed a significant Ml benefit with aspirin. ${ }^{9}$ Interestingly, in this study, $>70 \%$ of the patients had known dyslipidaemia, but only $51 \%$ of them received statins during the course of the study. ${ }^{9}$

In the HOT trial, allocation to aspirin was also associated with a significant $35 \% \mathrm{Ml}$ risk reduction. ${ }^{11}$ Yet, only $7 \%$ of the patients were treated with lipid-lowering drugs, and the mean total cholesterol was $235 \mathrm{mg} / \mathrm{dL}$, suggesting a non-negligible proportion of patients with hypercholesterolaemia who may have derived benefit from lipidlowering agents. ${ }^{11}$ In primary prevention trials, the use of statins is known to be associated with a $25 \%$ decrease in the risk of major vascular events for every $1 \mathrm{mmol} / \mathrm{L}$ decrease in the LDL cholesterol level (rate ratio with statin vs. placebo, 0.75; 95\% Cl 0.69-0.82). ${ }^{12}$
This statistically significant benefit was associated with an excellent safety profile and was not associated with the bleeding risks observed consistently throughout all aspirin trials.

Moreover, an intriguing observation regarding cholesterol levels and $\mathrm{Ml}$ benefit of aspirin in the primary prevention setting comes from the Physicians' Health Study, which ante-dated the availability of statins. ${ }^{13}$ In this trial, a significant interaction was noted between baseline cholesterol level and relative risk reduction for $\mathrm{MI}$, with greater benefit observed in patients with the highest baseline cholesterol levels. Hence, taken together, current evidence raises concerns that aspirin can significantly contribute to $\mathrm{Ml}$ prevention in patients when properly treated with lipid-lowering agents as per todays' practice and guidelines.

The recent results of the Reduction of Cardiovascular Events with Icosapent Ethyl-Intervention Trial (REDUCE-IT), where high-dose icosapent ethyl led in the primary prevention setting to a consistent reduction of the primary composite ischaemic endpoint, including cardiovascular death, non-fatal myocardial infarction, and non-fatal stroke, without a significant increase in bleeding risk-albeit with a higher incidence of atrial fibrillation or flutter whose implications and mechanisms need to be better understood — further highlights the key role of lipid-lowering agents even in patients in whom the median LDL cholesterol level was $75.0 \mathrm{mg} / \mathrm{dL}$ at baseline. ${ }^{14}$

Whether routine antiplatelet agents, other than aspirin, will still have a possible role in high-risk patients in the truly primary 
prevention setting remains unclear, but it appears rather unlikely given the well-known trade-off between risks and benefits observed consistently across all antithrombotic agents investigated so far.

The issue of the management of patients fulfilling the 1.5 prevention setting, i.e. in whom an atherosclerotic disorder has been established prior to the occurrence of an ischaemic event or to the development of related symptoms, still remains unresolved. A pragmatic approach in this setting might be a selected use of aspirin only for patients on the low bleeding risk spectrum in the hope that this strategy might maximize the benefits over the risks. ${ }^{15}$

The Effect of Ticagrelor on Health Outcomes in Diabetes Mellitus Patients Intervention Study (THEMIS, NCT01991795) is designed to evaluate the efficacy and safety of ticagrelor in $>20000$ patients aged 50 years or more with type 2 diabetes with known coronary artery disease but without a history of an $\mathrm{Ml}$ or stroke. Patients are being randomized to ticagrelor $60 \mathrm{mg}$ twice daily or placebo in a doubleblinded fashion. The primary endpoint is the composite of cardiovascular death, $\mathrm{Ml}$, or stroke at 48 months. Results of the THEMIS trial are expected in early 2019 and will greatly contribute to our current understanding about the future role of antiplatelet agents as a primary means to avoid the consequences of plaque rupture in patients who may have ongoing yet asymptomatic plaque rupture episodes. Meanwhile, we should get ready to say a farewell to aspirin even in asymptomatic patients in whom an atherosclerosis disorder is not established, irrespective of the anticipated risk of future ischaemic events or concomitant cardiovascular risk factors.

Conflict of interest: M.V. reports grants and personal fees from Abbott, Terumo, and Astrazeneca; personal fees from Chiesi, Bayer, Daiichi Sankyo, Amgen, and Alvimedica; and grants from Medicure, Biosensors, and Idorsia, outside the submitted work.

\section{References}

1. Vranckx $P$, Valgimigli M, Juni $P$, Hamm C, Steg PG, Heg D, van Es GA, McFadden EP, Onuma $Y$, van Meijeren C, Chichareon P, Benit E, Mollmann H, Janssens L, Ferrario M, Moschovitis A, Zurakowski A, Dominici M, Van Geuns RJ, Huber K, Slagboom T, Serruys PW, Windecker S, GLOBAL LEADERS Investigators. Ticagrelor plus aspirin for 1 month, followed by ticagrelor monotherapy for 23 months vs aspirin plus clopidogrel or ticagrelor for 12 months, followed by aspirin monotherapy for 12 months after implantation of a drug-eluting stent: a multicentre, open-label, randomised superiority trial. Lancet 2018;392:940-949.

2. Gaziano JM, Brotons C, Coppolecchia R, Cricelli C, Darius H, Gorelick PB, Howard G, Pearson TA, Rothwell PM, Ruilope LM, Tendera M, Tognoni G; ARRIVE Executive Committee. Use of aspirin to reduce risk of initial vascular events in patients at moderate risk of cardiovascular disease (ARRIVE): a randomised, double-blind, placebo-controlled trial. Lancet 2018;392:1036-1046.

3. Group ASC, Bowman L, Mafham M, Wallendszus K, Stevens W, Buck G, Barton J, Murphy K, Aung T, Haynes R, Cox J, Murawska A, Young A, Lay M, Chen F, Sammons E, Waters E, Adler A, Bodansky J, Farmer A, McPherson R, Neil A, Simpson D, Peto R, Baigent C, Collins R, Parish S, Armitage J. Effects of aspirin for primary prevention in persons with diabetes mellitus. N Engl J Med 2018;379:1529-1539.

4. McNeil Jj, Wolfe R, Woods RL, Tonkin AM, Donnan GA, Nelson MR, Reid CM, Lockery JE, Kirpach B, Storey E, Shah RC, Williamson JD, Margolis KL, Ernst ME,
Abhayaratna WP, Stocks N, Fitzgerald SM, Orchard SG, Trevaks RE, Beilin LJ, Johnston Cl, Ryan J, Radziszewska B, Jelinek M, Malik M, Eaton CB, Brauer D, Cloud G, Wood EM, Mahady SE, Satterfield S, Grimm R, Murray AM, ASPREE Investigator Group. Effect of aspirin on cardiovascular events and bleeding in the healthy elderly. N Engl J Med 2018;379:1509-1518.

5. Bibbins-Domingo K, U.S. Preventive Services Task Force. Aspirin use for the primary prevention of cardiovascular disease and colorectal cancer: U.S. Preventive Services Task Force Recommendation Statement. Ann Intern Med 2016;164: 836-845.

6. Piepoli MF, Hoes AW, Agewall S, Albus C, Brotons C, Catapano AL, Cooney MT, Corra U, Cosyns B, Deaton C, Graham I, Hall MS, Hobbs FDR, Lochen ML, Lollgen H, Marques-Vidal P, Perk J, Prescott E, Redon J, Richter DJ, Sattar N, Smulders Y, Tiberi M, van der Worp HB, van Dis I, Verschuren WMM, Binno S, ESC Scientific Document Group. 2016 European Guidelines on cardiovascular disease prevention in clinical practice: The Sixth Joint Task Force of the European Society of Cardiology and Other Societies on Cardiovascular Disease Prevention in Clinical Practice (constituted by representatives of 10 societies and by invited experts). Developed with the special contribution of the European Association for Cardiovascular Prevention \& Rehabilitation (EACPR). Eur Heart J 2016;37:2315-2381.

7. Mahmoud AN, Gad MM, Elgendy AY, Elgendy IY, Bavry AA. Efficacy and safety of aspirin for primary prevention of cardiovascular events: a meta-analysis and trial sequential analysis of randomized controlled trials. Eur Heart J 2019;40:607-617.

8. Antithrombotic Trialists' (ATT) Collaboration, Baigent C, Blackwell L, Collins R, Emberson J, Godwin J, Peto R, Buring J, Hennekens C, Kearney P, Meade T, Patrono C, Roncaglioni MC, Zanchetti A. Aspirin in the primary and secondary prevention of vascular disease: collaborative meta-analysis of individual participant data from randomised trials. Lancet 2009;373:1849-1860.

9. Ikeda Y, Shimada K, Teramoto T, Uchiyama S, Yamazaki T, Oikawa S, Sugawara M, Ando K, Murata M, Yokoyama K, Ishizuka N. Low-dose aspirin for primary prevention of cardiovascular events in Japanese patients 60 years or older with atherosclerotic risk factors: a randomized clinical trial. JAMA 2014;312: 2510-2520.

10. Valgimigli M, Costa F, Lokhnygina Y, Clare RM, Wallentin L, Moliterno DJ, Armstrong PW, White HD, Held C, Aylward PE, Van de Werf F, Harrington RA, Mahaffey KW, Tricoci P. Trade-off of myocardial infarction vs. bleeding types on mortality after acute coronary syndrome: lessons from the Thrombin Receptor Antagonist for Clinical Event Reduction in Acute Coronary Syndrome (TRACER) randomized trial. Eur Heart / 2017;38:804-810.

11. Hansson L, Zanchetti A, Carruthers SG, Dahlof B, Elmfeldt D, Julius S, Menard J, Rahn $\mathrm{KH}$, Wedel H, Westerling S. Effects of intensive blood-pressure lowering and low-dose aspirin in patients with hypertension: principal results of the Hypertension Optimal Treatment (HOT) randomised trial. HOT Study Group. Lancet 1998;351:1755-1762.

12. Collins R, Reith C, Emberson J, Armitage J, Baigent C, Blackwell L, Blumenthal R, Danesh J, Smith GD, DeMets D, Evans S, Law M, MacMahon S, Martin S, Neal B, Poulter N, Preiss D, Ridker P, Roberts I, Rodgers A, Sandercock P, Schulz K, Sever P, Simes J, Smeeth L, Wald N, Yusuf S, Peto R. Interpretation of the evidence for the efficacy and safety of statin therapy. Lancet 2016;388:2532-2561.

13. Steering Committee of the Physicians' Health Study Research Group. Final report on the aspirin component of the ongoing Physicians' Health Study. N Engl J Med 1989;321:129-135.

14. Bhatt DL, Steg PG, Miller M, Brinton EA, Jacobson TA, Ketchum SB, Doyle RT Jr, Juliano RA, Jiao L, Granowitz C, Tardif JC, Ballantyne CM, REDUCE-IT Investigators. Cardiovascular risk reduction with icosapent ethyl for hypertriglyceridemia. N Engl J Med 2018;in press.

15. Costa F, van Klaveren D, James S, Heg D, Raber L, Feres F, Pilgrim T, Hong MK, Kim HS, Colombo A, Steg PG, Zanchin T, Palmerini T, Wallentin L, Bhatt DL, Stone GW, Windecker S, Steyerberg EW, Valgimigli M, PRECISE-DAPT Study Investigators. Derivation and validation of the predicting bleeding complications in patients undergoing stent implantation and subsequent dual antiplatelet therapy (PRECISE-DAPT) score: a pooled analysis of individual-patient datasets from clinical trials. Lancet 2017;389:1025-1034. 